\title{
Measurement of joint inflammation in rheumatoid arthritis with indium-111 chloride
}

\author{
Robert H Shmerling, J Anthony Parker, William D Johns, David E Trentham
}

\begin{abstract}
Studies in the collagen and rabbit models of arthritis have indicated that indium-111 chloride $\left({ }^{111} \mathrm{InCl}_{3}\right)$ scintigraphy objectively measures synovial inflammation. Indium-111 chloride scans, with imaging three days after $19 \mathrm{MBq}$ intravenous injection, were performed on 21 patients with definite or classical rheumatoid arthritis (RA), all of whom were functional class II. Standard clinical indices of disease activity were recorded at the time of imaging by the same investigator, who was unaware of the results of joint scans. In addition, eight patients with severe osteoarthritis, four of whom were considered to need hip or knee joint replacement, were similarly scanned. In each patient 16 joints were graded as 0 to 5 , based on increasing degrees of ${ }^{111} \mathrm{InCl}_{3}$ uptake, by a single investigator blinded to the patient's diagnosis and clinical status. In the group with RA significant correlations were observed between individual joint uptake on scan and peripheral joints with swelling, joints reported to be painful, and joints with any abnormality on physical examination. In the group with osteoarthritis joints positive on scan correlated with the presence of pain. A total scan score (sum of individual joint scores) was calculated for each patient. In the patients with $R A$ values ranged from 0 to 42 with a mean (SEM) of 20.7 (2.7) and correlated with the number of swollen joints and decreasing grip strength. In the group with osteoarthritis the mean total scan score $(9.2(1.5)$, range $3-14)$ was significantly lower than in the patients with RA. These data show that ${ }^{111} \mathrm{InCl}_{3}$ scanning can measure joint involvement by RA.
\end{abstract}

Department of Medicine, Harvard Medical School, and the Division of Rheumatology, Beth Israel Hospital, Boston, MA 02215, USA

R H Shmerling

D E Trentham

Department of Radiology, Harvard Medical School, and the Division of Nuclear Medicine, Beth Israel Hospital, Boston, MA 02215, USA J A Parker

W D Johns

Correspondence to: Dr Robert H Shmerling, Beth Israel Hospital, YA-401B, 330 Brookline Avenue, Boston, MA 02215, USA.

Accepted for publication 19 May 1989 such as the number of swollen or painful joints, are subjective and may not reflect changes in this disease. Currently available scintigraphic techniques, such as technetium- $99 \mathrm{~m}$ pertechnetate, have been advocated for this purpose ${ }^{1-5}$ but have received criticism owing to difficulties with interpretation and non-specificity. ${ }^{6}$

Other radiopharmaceuticals have been sought which might selectively identify inflamed synovium. The radiocations, gallium-67 $\left({ }^{67} \mathrm{Ga}\right)^{78}$ and indium-111 ( $\left.{ }^{111} \mathrm{In}\right)^{9}{ }^{10}$ have been proposed because they possess a high affinity for iron binding proteins. ${ }^{11-15}$ Synovial iron is increased in $\mathrm{RA},{ }^{16-20}$ and a close correlation between the inflammatory infiltrate and synovial ferritin content has been described. ${ }^{16} 20$

Gallium-67 has been investigated as a joint imaging agent in $\mathrm{RA}^{8}$ and shown, in a rabbit model of arthritis, to accumulate preferentially in the inflamed synovial tissue. ${ }^{7}$ Like ${ }^{67} \mathrm{Ga}$ citrate, ${ }^{111} \mathrm{InCl}_{3}$ has favourable gamma emissions and a short half life of $2 \cdot 8$ days. ${ }^{11}$ Indium-111 chloride readily identifies cells expressing transferrin receptors, ${ }^{13-15}$ which are uniform markers of cell division, ${ }^{21} 22$ and competes more specifically than gallium for the iron binding site of transferrin. ${ }^{12}$ Previous studies showed that ${ }^{111} \mathrm{InCl}_{3}$ radioimaging accurately defined the arthritic response of rats to immunisation with collagen. ${ }^{9}$ A comparison with technetium$99 \mathrm{~m}$ dicarboxypropane-diphosphonic acid joint scanning in two patients with RA suggested that the ${ }^{111} \mathrm{InCl}_{3}$ joint scan more closely reflected their clinical status. ${ }^{9}$ Similar attributes were found for ${ }^{111} \mathrm{InCl}_{3}$ imaging in a rabbit model of antigen induced arthritis, where the histological severity of synovitis correlated closely with uptake. ${ }^{10}$ This study was conducted to evaluate further ${ }^{111} \mathrm{InCl}_{3}$ joint scintigraphy in patients with arthritis.

\section{Patients and methods PATIENTS}

Twenty one outpatients fulfilling the American Rheumatism Association criteria for definite or classical $\mathrm{RA}^{23}$ and eight patients with clinical and radiographic features of severe osteoarthritis of the hips and knees were recruited from the rheumatology clinic at our institution. The patients with RA were concurrently receiving non-steroidal anti-inflammatory drugs (19 patients), oral methotrexate 7.5 to $15 \mathrm{mg}$ weekly (nine patients), prednisone $10 \mathrm{mg}$ or less daily (eight patients), and parenteral gold (three patients). The patients with osteoarthritis were receiving non-steroidal anti-inflammatory drug treatment and had not received intra-articular injections. No patients were receiving iron treatment.

\section{EVALUATIONS} and then ${ }^{111} \mathrm{InCl}_{3}$ joint scintigraphy was carried out as previously described. ${ }^{9}$ Each patient received $19 \mathrm{MBq}{ }^{111} \mathrm{InCl}_{3}$ intravenously, which exposes the patient to $2.5 \mathrm{mGy}$ of whole body radiation (equivalent to the radiation exposure of 10 chest roentgenographs). Sixteen joint regions (hands, wrists, elbows, shoulders, hips, knees, ankles, and feet) were imaged at three
Informed consent was obtained from patients 
days for five minutes in the late morning with an Anger scintillation camera interfaced to a computer. All views were anterior projections. Total scanning time was 30 to 45 minutes with total counts in joint regions of interest of 1000 to 5000 . Ten per cent windows were set to detect the 173 and $247 \mathrm{keV}$ peaks of ${ }^{111} \mathrm{In}$. Data were stored in a $128 \times 128$ matrix. The stored computer images were analysed independently by two observers (JAP and WDJ), who were unaware of the patients' diagnosis or clinical status. A value of 0 to 5 was assigned to each joint, depending on the degree of uptake, as follows: $0=$ negative; $1=$ probably negative; 2 =probably positive; 3 =positive, faint; $4=$ positive; $5=$ positive, marked. By summating each patient's 16 joint scores, a total scan score was calculated. A computerised score was obtained from a ratio of the activity over the joint to that over an adjacent soft tissue region, after correction for background outside the patient. $^{9}$

At the time of imaging a full examination was made of all the patients with $\mathrm{RA}$ by one investigator (RHS). Clinical data were recorded without knowledge of scan results. The methods used were those developed by the cooperating clinics committee of the American Rheumatism Association $^{24}$ and used in other studies. ${ }^{25-28}$ Grip strength was measured with the same folded sphygmomanometer after the cuff had been inflated to $20 \mathrm{mmHg}$. The degree of overall synovitis was graded as $0,1,2$, or 3 , according to a previously formulated scale. ${ }^{29}$ The time required to walk $15 \mathrm{~m}$, the duration of morning stiffness, and the number of antiinflammatory and analgesic tablets or capsules ingested daily were recorded. The patient's global assessment of status was graded. ${ }^{25}$ For the patients with osteoarthritis the investigator conducted a chart review and an examination for diarthrodial joints with pain, swelling, or deformity. In both patient groups a joint was considered to be abnormal on examination if swelling, deformity, pain on palpation or passive motion, or a restricted range of motion was detected.

\section{STATISTICAL ANALYSIS}

Correlations between positive (score $\geqslant 2$ ) or negative (score $\leqslant 1$ ) scans and swelling, pain, or any abnormality on examination were calculated with the $\chi^{2}$ test of association. Correlations between total scan score and clinical disease variables were calculated with the Pearson product-moment correlation coefficient. Comparison between the mean total scan score of patients with RA and osteoarthritis was made with Student's two tailed $t$ test. A p value of $<0.05$ was accepted as evidence of significance.

\section{Results}

All 21 patients with RA were judged to be functional class II. ${ }^{30}$ Table 1 presents the other clinical characteristics of these patients and of the eight patients with osteoarthritis. Four of the eight patients with osteoarthritis had been advised to have hip or knee replacement, but

Table 1: Demographic and clinical characteristics of the 21 patients with rheumatoid arthritis and the eight with osteoarthritis undergoing ${ }^{11} \mathrm{InCl}_{3}$ joint scanning

\section{Rheumatoid arthritis}

Average age (range)

Number female

Average years of disease duration (range)

Average number of painful joints (range)

Average number of swollen joints (range)

Average time (s) to walk $15 \mathrm{~m}$ (range)

Average grip strength (mmHg) (range)

$52(35-70)$

$8 \cdot 1(0 \cdot 5-17)$

$6(1-10)$

$4 \quad(0-10)$

$11 \cdot 2(8 \cdot 5-15 \cdot 2)$

$93(33-190)$

Osteoarthritis

Average age (range)

Average number of painful joints (range)

$67 \quad(48-76)$

$4 \quad(2-6)$

none had undergone surgery. Figures 1-3 show examples of ${ }^{111} \mathrm{InCl}_{3}$ scans.

A total of 444 joint regions from the patients with RA and osteoarthritis was considered by both observers to be visualised sufficiently well on scan to allow scoring. In $183(41 \%)$ there was exact agreement in score. Disagreements by one to five grades occurred in $131(30 \%), 70(16 \%)$, $39(9 \%), 20(5 \%)$, and $1(0 \cdot 2 \%)$ joints respectively. Thus there was agreement within one score grade in $314(71 \%)$ joints, and the two observers' scores were highly correlated $\left(\chi^{2}=158\right.$, $\mathrm{p}<0.0001)$. Scoring of the ankles and feet differed markedly between observers, however. One observer had an average score of 1.38 for the ankles and feet, while the other had an average score of $3 \cdot 00$. Fourteen of the 21 disagreements by four or five score units occurred in the ankles or feet.

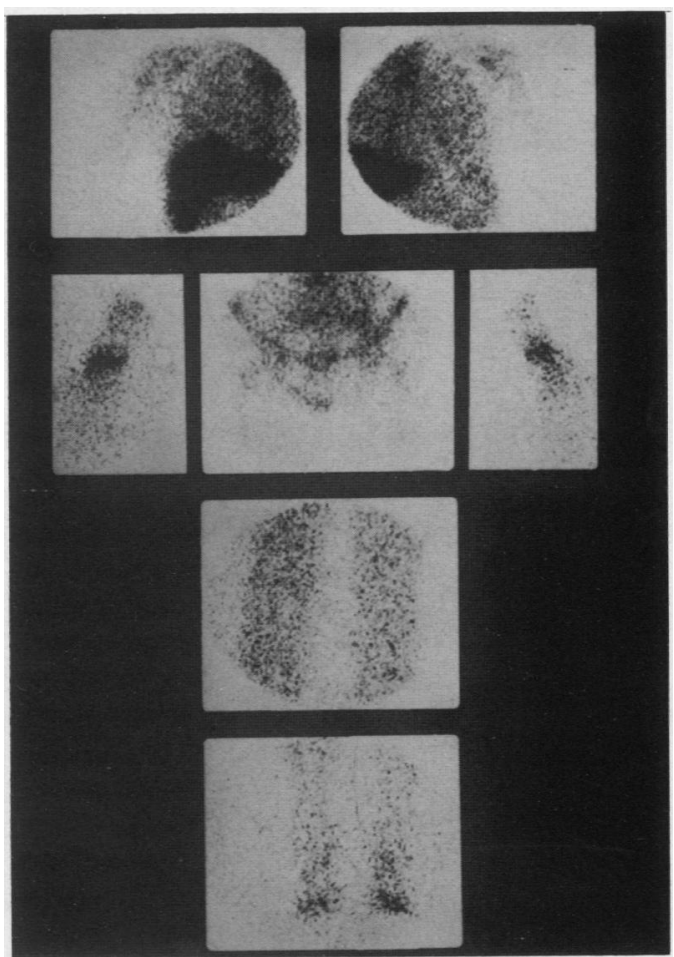

Figure 1: Anterior images of the shoulders, hands, hips, knees, and feet, obtained three days after intravenous injection of ${ }^{\prime \prime}$ In $\mathrm{Cl}_{3}$, in a patient with rheumatoid arthritis. There is symmetrical, markedly positive uptake in the wrists and forefeet. Note the activity in the liver and bone marrow. In this patient the shoulders, wrists, and feet were painful and swelling was present in the wrists and proximal interphalangeal joints. 


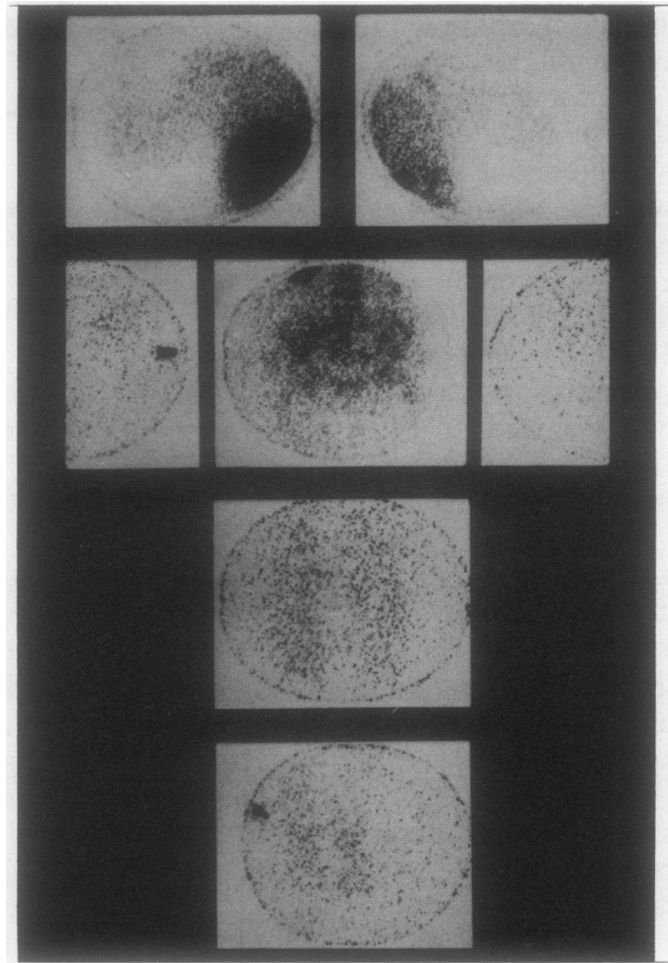

Figure 2: Anterior images of the shoulders, hands, hips, knees, and feet, obtained three days after intravenous injection of ${ }^{111} \mathrm{InCl}_{3}$, in a patient with osteoarthritis. There is only faint activity over the joints. A radioactive marker has been placed alongside the right hand and foot. In this patient the right wrist, left knee, and left shoulder were painful, but no joints were swollen.

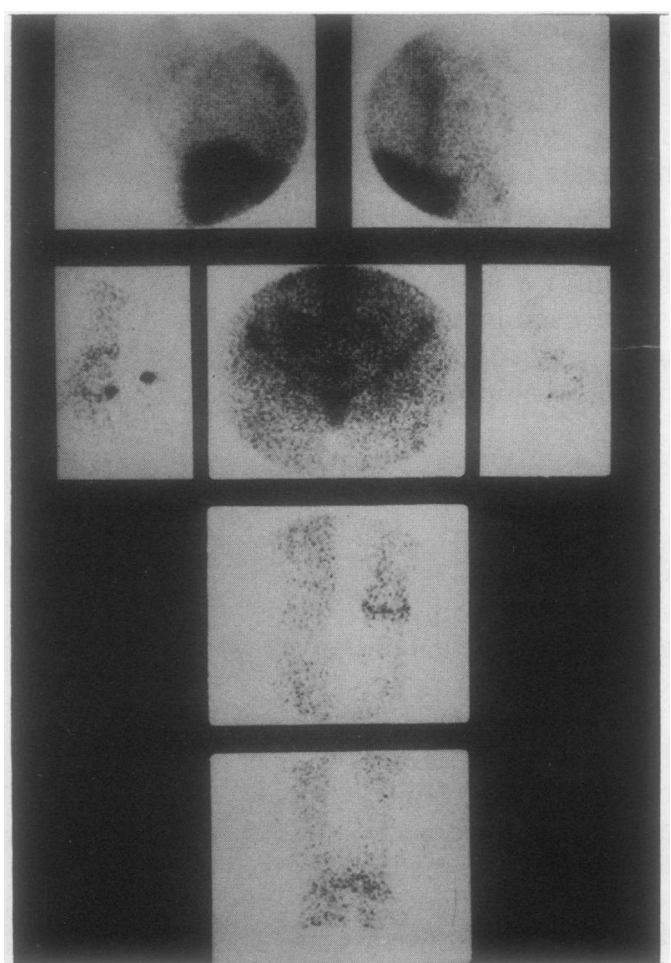

Figure 3: Anterior images of the shoulders, hands, hips, knees, and feet, obtained three days after intravenous injection of ${ }^{111}$ InCl $_{3}$, in a patient with rheumatoid arthritis. There is markedly positive uptake in the left knee, positive uptake in the right wrist, hand, foot, and left ankle, and
faintly positive uptake in the left wrist, hand, and foot. A faintly positive uptake in the left wrist, hand, and foot. A
radioactive marker has been placed alongside the right hand. In this patient the right shoulder, both elbows, wrists, hands, knees, ankles, and feet were painful and swelling was present in both wrists, hands, and the left knee and ankle.
The computerised score was difficult to implement owing to the varying background adjacent to the joint. An attempt was made to pick a representative region, but the computer calculations were heavily dependent on region selection. There was almost no correlation between the computer score and the subjective scan score, apparently because of background uptake. Subjective scan results depicted in the remainder of this paper, therefore, represent the readings of the senior radiologist (JAP).

\section{STUDIES IN RA}

Table 2 compares clinical findings and ${ }^{111} \mathrm{InCl}_{3}$ scans in the patients with RA. Of 248 individual joints, excluding the shoulders and hips, 77 were considered to be swollen. Forty four $(57 \%)$ of the swollen joints were positive on ${ }^{111} \mathrm{InCl}_{3}$ scan. Of the 171 peripheral joints without swelling, $47(27 \%)$ were positive. The overall agreement (positive scan with swelling present and negative scan with swelling absent) was $68 \%$. The correlation between joint swelling and scan results was significant $\left(\chi^{2}=18 \cdot 8\right.$, $\mathrm{p}<0.0001)$. Similarly, a highly significant $\left(\chi^{2}=\right.$ $20.9, \quad p<0.0001)$ correlation was observed between individual joints reported to be painful and considered positive on scan. This assessment included the shoulders and hips. The overall agreement between painful joints and scan results was $65 \%$. Indium- 111 chloride joint scanning also correlated with joints that were both swollen and described as painful $\left(\chi^{2}=35 \cdot 5\right.$, $\mathrm{p}<0.0001)$ and with joints that showed abnormalities on physical examination $\left(\chi^{2}=6 \cdot 1\right.$, $\mathrm{p}<0.02)$. The overall agreement was $73 \%$ for swollen, painful joints and $55 \%$ for abnormal

Table 2: Clinical and ${ }^{111} \mathrm{InCl}_{3}$ radioimaging assessments in 21 patients with rheumatoid arthritis*

\begin{tabular}{|c|c|c|c|}
\hline \multicolumn{2}{|l|}{$\begin{array}{l}\text { Clinical } \\
\text { variable }\end{array}$} & $\begin{array}{l}\text { Joints positive } \\
\text { on } \mathrm{III}_{\mathrm{InCl}} \text { scan } \\
\mathrm{No}(\%)\end{array}$ & $p$ Value \\
\hline $\begin{array}{c}\text { Swelling } \\
\text { Present } \\
\text { Absent }\end{array}$ & $\begin{array}{l}(\mathrm{n}=77) \\
(\mathrm{n}=171)\end{array}$ & $\begin{array}{l}44(57) \\
47(27)\end{array}$ & $<0.0001$ \\
\hline $\begin{array}{l}\text { Pain } \\
\text { Present } \\
\text { Absent }\end{array}$ & $\begin{array}{l}(\mathrm{n}=134) \\
(\mathrm{n}=198)\end{array}$ & $\begin{array}{l}69(51) \\
52(26)\end{array}$ & $<0.0001$ \\
\hline $\begin{array}{l}\text { Swelling an } \\
\text { Present } \\
\text { Absent }\end{array}$ & $\begin{array}{c}(n=198) \\
\text { pain } \\
(n=50) \\
(n=198)\end{array}$ & $\begin{array}{l}52(20) \\
37(74) \\
54(27)\end{array}$ & $<0.0001$ \\
\hline $\begin{array}{c}\text { Examination } \\
\text { Abnormal } \\
\text { Normal }\end{array}$ & $\begin{array}{l}(n=153) \\
(n=179)\end{array}$ & $\begin{array}{l}68(44) \\
55(31)\end{array}$ & $<0.02$ \\
\hline
\end{tabular}

${ }^{*}$ A total of 252 peripheral joints (excluding the shoulders and hips) were examined for swelling and 336 joints for pain and any hips) were examined for swelling and 336 joints for pain and any abnormality. The number of joints on which comparisons are joints from the imaged field.

Table 3: Number (\%) of joints considered positive on ${ }^{11}{ }^{1 n C l} l_{3}$ scan in 21 patients with rheumatoid arthritis*

\begin{tabular}{ll}
\hline foint & \multicolumn{1}{l|}{ InCl $l_{3}$ scan } \\
& Number positive/total $(\%)$ \\
\hline Hands & $14 / 42(33)$ \\
Wrists & $23 / 42(55)$ \\
Elbows & $2 / 38(5)$ \\
Shoulders & $21 / 42(50)$ \\
Hips & $8 / 42(19)$ \\
Knees & $17 / 42(40)$ \\
Ankles & $21 / 42(50)$ \\
Feet & $19 / 42(45)$
\end{tabular}

${ }^{*}$ As described in table 2 , analysis was performed on a total of 332 joints. 
joints. Table 3 shows the number of positive scans in the various joints. There was no significant association between the computerised scores and any of the clinical variables.

The $\chi^{2}$ test of association was also used to examine relations between clinical variables. After exclusion of pain in hips and shoulders joint pain was compared with swelling. Although these clinical variables were associated with one another $\left(\chi^{2}=11 \cdot 2, p<0.001\right)$, only 50 of 105 (48\%) painful joints were also swollen. The overall clinical agreement between pain and swelling was $66 \%$.

\section{STUDIES IN OSTEOARTHRITIS}

Among the eight patients with osteoarthritis, nine $(30 \%)$ of the 30 joints reported as painful were positive on joint scan; of the 98 asymptomatic joints, nine $(9 \%)$ were positive. The overall agreement was $77 \%$. There was a significant $\left(\chi^{2}=8 \cdot 2, p<0.01\right)$ correlation between joints positive on scan and the presence of pain. Positive scans were not significantly associated with abnormalities on joint examination or the presence of swelling, which was rare. Joints positive on scan consisted of eight wrists, four knees, two hands, two hips, and two shoulders. It was not possible to distinguish between carpometacarpal and radiocarpal uptake in the positive wrists.

\section{TOTAL SCAN SCORE}

The mean (SEM) total scan score in the patients with RA was $20 \cdot 7(2 \cdot 7)$ (range $0-42$ ), while the mean score in the patients with osteoarthritis was $9.2(1.5)$ (range 3-14). The difference between these means was significant $(p<0.001)$. In the group with $\mathrm{RA}$ the total scan score correlated with the number of swollen joints (fig 4) and was inversely related to grip strength (fig 5). In neither group was there a significant association between the total scan score and other clinical or demographic variables measured.

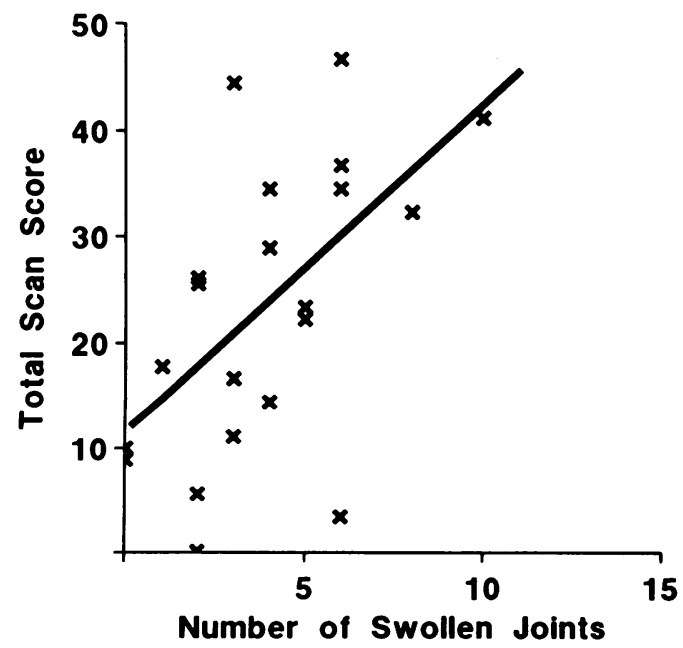

Figure 4: Regression analysis $(r=0.562, p<0.01)$ of the total scan score and the number of peripheral joints with swelling in the individual patients with rheumatoid arthritis.

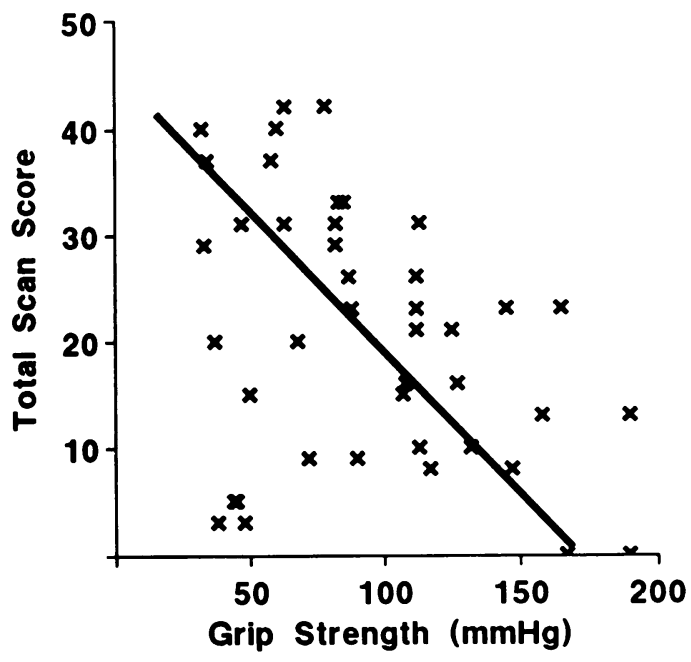

Figure 5: Regression analysis $(r=-0.373, p<0.02)$ of the total scan score and bilateral grip strengths in the individual patients with rheumatoid arthritis.

\section{Discussion}

In this study joint uptake of intravenously administered ${ }^{111} \mathrm{InCl}_{3}$ correlated significantly with conventional clinical measures of arthritis in a group of patients with RA who had varying duration of disease, pattern of joint involvement, and type of treatment. These findings support the suggestion that transferrin receptors are abundant in inflamed synovium ${ }^{31}$ and may indicate an important role for iron in the pathogenesis or perpetuation of the chronic synovitis seen in $\mathrm{RA} .{ }^{16-20}$ The ability of ${ }^{111} \mathrm{InCl}_{3}$ to identify clinically active joints of patients with RA may make it a useful technique to detect, quantify, and monitor synovitis in this disease, and possibly in other conditions of chronic joint inflammation.

The sensitivity and specificity of diagnostic scanning with ${ }^{111} \mathrm{InCl}_{3}$ are difficult to calculate from this study. As there is no standard by which the cause of symptoms or signs of joint inflammation may be determined, even in patients meeting criteria for RA, we cannot rule out subclinical rheumatoid synovitis in a joint that is asymptomatic but positive on joint scan. Similarly, joints that were symptomatic or swollen but negative on ${ }^{111} \mathrm{InCl}_{3}$ scan may represent poor sensitivity, or may indicate that a process other than rheumatoid synovitis explains the clinical findings. The presence of pain and swelling correlated imperfectly with one another, again making it difficult to estimate the accuracy of ${ }^{111} \mathrm{InCl}_{3}$ joint scanning.

Patients with osteoarthritis generally had negative ${ }^{111} \mathrm{InCl}_{3}$ joint scans. The positive joint scans in these patients may represent subclinical inflammation ('inflammatory osteoarthritis') or may, alternatively, represent false positive results.

There was total disagreement (disagreement by four or five categories) between observers in $5 \%$ of readings. More than half of this disagreement was found to be due to a marked difference in interpretations of readings for ankles and feet. Caution also had to be used in interpreting shoulder and hip scans owing to the 
occasional presence of contiguous bone marrow uptake. New criteria have been developed for this group of patients, which will be evaluated in further studies in an attempt to improve the precision of interpretation.

Scintigraphic experience with intravenously administered ${ }^{111} \mathrm{InCl}_{3}$ in patients with osteomyelitis has shown that this technique accurately detects infection. ${ }^{32}{ }^{33}$ Interestingly, positive scans without infection were encountered in two patients with inflammatory arthritis. ${ }^{32}$

Although this study is the first systematically to relate clinical features of RA and osteoarthritis to ${ }^{111} \mathrm{InCl}_{3}$ scan results, it possesses the limitations commonly associated with scintigraphy. ${ }^{34}$ As synovial fluid or biopsy material was not obtained from the joints of these patients we cannot be certain that uptake indicated inflammation. We have not repeated scans on individual patients to analyse whether changes in joint scans correlate with alterations in clinical status or treatment, nor have we followed up patients for long enough to know whether joints considered false positive on scan will eventually develop clinical disease.

The clinical evaluation of disease activity in RA is hampered by a lack of objective measures. Although the technique is sufficiently safe and the results in this study are promising, they must be considered preliminary. Further analysis will be required to determine the true value of ${ }^{111} \mathrm{InCl}_{3}$ joint scanning in individual patients with RA.

The authors wish to thank Ms Barbara Brown for manuscript preparation. This work was supported in part by USPHS research grants AR-38331 and AM-36356, the Charles A Dana Research Institute, and the Harvard-Thorndike Laboratory of Beth Israel Hospital. Data analysis was performed on the Core laboratory computer.

1 Bergmann H, Kolarz G. Pertechnetate uptake of joints in rheumatoid arthritis. Eur 7 Nucl Med 1976; 1: 205-10.

2 Boerbooms A M T, Buys W C A M. Rapid assessment of $99 \mathrm{~m}$ Tc-pertechnetate uptake in the knee joint as a parameter of Tc-pertechnetate uptake in the knee joint as a parameter

3 Wahner H W, O'Duffy J D. Peripheral joint scanning with technetium pertechnetate. Application in clinical practice. Mayo Clin Proc 1976; 51: 525-31.

4 Alarcon-Segovia D, Tovar E, Adame M A, Trujeque M. The clinical application of scintillation scanning of joints with technetium- $99 \mathrm{~m}$. Proceedings of the IVth panamerican congress of rheumatology. Amsterdam: Excerpta Medica 1967; 165: 216-24. (International congress series.)

5 Park H M, Terman S A, Ridolfo A S, Wellman H N. A quantitative evaluation of rheumatoid arthritic activity with TC-99mHEDP. $7 \mathrm{Nucl}$ Med 1977; 18: 973-6.

6 Green F A. Joint scintiscans: present status. 7 Rheumatol 1979; 6: 370-3.

7 Tannenbaum H, Rosenthal L, Greenspoon M, Ramelson $\mathrm{H}$. Quantitative joint imaging using ${ }^{67}$ gallium citrate in a rabbi model of zymosan induced arthritis. 7 Rheumatol 1984; 11 : 687-91
8 McCall I W, Sheppard H, Haddaway M, Park W M, Ward $\mathrm{D} \mathrm{J}$. Gallium 67 scanning in rheumatoid arthritis. $\mathrm{Br} \mathcal{F}$ Radiol 1983; 56: 241-3.

9 de Sousa M, Bastos A L, Dynesius-Trentham R, et al. Potential of indium-111 to measure inflammatory arthritis. f Rheumatol 1986; 13: 1108-16.

10 Zalutsky M R, de Sousa M, Venkatesan P, Shortkroff S, Zuckerman J, Sledge C. Evaluation of indium-111 chloride as a radiopharmaceutical for joint imaging in a rabbit model of arthritis. Invest Radiol 1987; 22: 733-40.

11 Thakur M L. Gallium-67 and indium-111 radiopharmaceuticals. Int $\mathcal{f}$ Appl Radiat Isot 1977; 28: 183-201.

12 Kulprathipanja S, Hnatowich D J, Beh R, Elmaleh D. Formation constants of gallium- and indium-transferrin. Int 7 Nucl Med Biol 1979; 6: 138-41.

13 Graber S E, Hurley P J, Heyssel R M, McIntyre P A Behavior of iron-, indium-, and iodine-labeled transferrin in the pregnant rat. Proc Soc Exp Biol Med 1970; 133: 1093-6.

14 Beamish M R, Brown E B. The metabolism of transferrin bound ${ }^{111}$ In and ${ }^{59} \mathrm{Fe}$ in the rat. Blood 1974; 43: 693-701.

15 Beamish $M$ R, Brown E B. A comparison of the behavior of and rat reticulocytes. Blood 1974; 43: 703-11.

16 Muirden K D. The anaemia of rheumatoid arthritis: the significance of iron deposits in the synovial membrane. Australian Annals of Medicine 1970; 2: 94-104.

17 Mowat A G, Hothersall T E, Aitchinson W R C. Nature of anaemia in rheumatoid arthritis. XI. Changes in iron metabolism induced by the administration of corticotrophin Ann Rheum Dis 1969; 28: 303-9.

18 Blake D R, Hall N D, Bacon P A, Dieppe P A, Halliwell B, Gutteridge J M C. The importance of iron in rheumatoid disease. Lancet 1981; ii: 1142-3.

19 Rowley D A, Halliwell B. Formation of hydroxyl radicals from hydrogen peroxide and iron salts by superoxide- and ascorbate-dependent mechanisms: relevance to the pathology ascorbate-dependent mechanisms: relevance to the pat

20 Blake D R, Gallagher P J, Potter A R, Bell M J, Bacon P A The effect of synovial iron on the progression of rheumatoid disease. Arthritis Rheum 1984; 27: 495-501.

21 Trowbridge I S, Omary M B. Human cell surface glycoprotein related to cell proliferation is the receptor for transferrin. Proc Natl Acad Sci USA 1981; 78: 3039-43.

22 Sutherland R, Delia D, Schneider C, Newman R, Kemshead $J$, Greaves $M$. Ubiquitous cell-surface glycoprotein on tumor cells is proliferation-associated receptor for transferrin. Proc Natl Acad Sci USA 1981; 78: 4515-9.

23 Ropes M W, Bennett G A, Cobb S, Jacox R, Jessar R A Revision of diagnostic criteria for rheumatoid arthritis. Bull Revision of diagnostic criteria

24 Cooperating clinics committee of the American Rheumatism Association. A seven-day variability study of 499 patients with peripheral rheumatoid arthritis. Arthritis Rheum 1965 8: $302-34$

25 Trentham D E, Belli J A, Anderson R J, et al. Clinical and immunologic effects of fractionated total lymphoid irradiation in refractory rheumatoid arthritis. $N$ Engl $\mathcal{F}$ Med 1981 305: $976-82$.

26 Weinblatt M E, Coblyn J S, Fox D A, et al. Efficacy of low dose methotrexate in rheumatoid arthritis. $N$ Engl 7 Med 1985; 312: 818-22.

27 Weinblatt M E, Coblyn J S, Fraser P A, et al. Cyclosporin A treatment of refractory rheumatoid arthritis. Arthritis Rheum 1987; 30: 11-17.

28 Trentham D E Belli J A, Bloomer W D, et al , 2,000centigray total lymphoid irradiation for refractory rheumatoid arthritis. Arthritis Rheum 1987; 30: 980-7.

29 Trentham D E, Dynesius R A, Rocklin R E, David J R. Cellular sensitivity to collagen in rheumatoid arthritis. $N$ Engl F Med 1978; 299: 327-32.

30 Steinbrocker O, Traeger $\mathrm{C} \mathrm{H}$, Batterman R C. Therapeutic criteria in rheumatoid arthritis. FAMA 1949; 140: 659-62.

31 de Sousa $M$, Dynesius-Trentham R, Mota-Garcia F, da Silva M T, Trentham D E. Activation of rat synovium by iron. Arthritis Rheum 1988; 31: 653-61.

32 Iles S E, Ehrlich L E, Saliken J C, Martin R H. Indium-111 chloride scintigraphy in adult osteomyelitis. $\mathrm{f} \mathrm{Nucl} \mathrm{Med}$ 1987; 28: 1540-5.

33 Sayle B A, Fawcett H D, Wilkey D J, Cierny G III, Made $\mathrm{J} T$. Indium-111 chloride imaging in chronic osteomyelitis 34 Hoffer P B, Genant H K. Radionuclide joint imaging. Semı Nucl Med 1976; 6: 121-37. 